\title{
MIGRAÇÃO, ATIVIDADE ECONÔMICA E REORGANIZAÇÃO DA POPULAÇÃO NO ESPAÇO: UM ESTUDO SOBRE A SERICICULTURA PARANAENSE
}

\author{
Cláudia Siqueira Baltar (Ciências Sociais - UEL) ${ }^{1}$ \\ Ronaldo Baltar (Ciências Sociais - UEL) ${ }^{2}$
}

\section{RESUMO}

O processo de ocupação territorial e demográfica do estado do Paraná, desde o século XIX, tem sido marcado por diferentes processos migratórios. Neste contexto, a sericicultura é um caso que permite discutir elementos sobre a relação entre migração, atividade econômica e a reorganização espacial da população. A produção do bicho-daseda, no Brasil desde 1848, acompanhou a dinâmica cafeeira. Chegou ao Paraná na década de 1930, com o fluxo migratório que ocupou e delineou a região Norte do Paraná. Inicialmente, atividade de colonos japoneses, a sericicultura passou a ser atividade de produtores rurais familiares diversos. O Brasil tornou-se um dos principais produtores mundiais de seda no século XX, sendo o estado de São Paulo o principal produtor de casulos até 1980, quando essa posição é assumida pelo Paraná que, desde então, mantem-se como principal exportador brasileiro, destacando a região Noroeste paranaense, onde se localiza o Vale da Seda. O presente trabalho, a partir do debate acerca do tema, aponta a importância de se pensar as dinâmicas demográfica e territorial em função da expansão de atividades econômicas complementares, que, embora não apresentem grandes impactos nacionais, contribuem para tornar mais complexos os processos migratórios, econômicos, políticos e sociais no âmbito regional e local.

Palavras-chave: Migração; reorganização espacial; sericicultura

\section{INTRODUÇÃO}

O trabalho que se apresenta aqui insere-se numa agenda de pesquisa que vem sendo desenvolvida pelo Observatório das Migrações de Londrina tem como principal problema de investigação as configurações, conexões e significados, passados e atuais, das migrações internas e internacionais que se realizaram e se realizam no território do estado do Paraná.

Nesse sentido, com base em diferentes referências historiográfica voltada para o estado do Paraná (BALHANA et al., 1969; NADALIN, 2002; WACHOWICZ, 2002), o processo de ocupação e formação social do estado do Paraná, desde o século XIX, tem sido marcado por diferentes processos migratórios e por um complexo processo de redistribuição populacional e ocupação territorial, nem sempre uníssono e consensual, articulando o desenvolvimento e expansão de atividades econômicas e a confluência de diferentes fluxos migratórios, envolvendo migrantes nacionais e estrangeiros, em dimensões territoriais internas e

\footnotetext{
${ }^{1}$ Email: cbaltar@uel.br.

${ }^{2}$ Email: baltar@uel.br.
} 


\section{SEMINÁRIO DE PESQUISA EM CIÊNCIAS HUMANAS - SEPECH \\ Humanidades, Estado e desafios didático-científicos \\ Londrina, 27 a 29 de julho de 2016}

Essa articulação é tomada aqui como um pano-de-fundo para o estudo do próprio processo de ocupação das diferentes regiões que compõem o território paranaense, com destaque para o desenvolvimento das diferentes atividades econômicas, para a redistribuição espacial da população, a partir das migrações interestaduais, intra-estaduais e internacionais e para a atuação diferenciada de atores públicos e privados, levada a cabo através de políticas econômicas e de desenvolvimento e empreendimentos de imigração e colonização.

O objetivo central deste trabalho volta-se para a consideração do desenvolvimento da sericicultura no estado do Paraná, como um estudo de caso que permite discutir esses vários elementos sobre a relação entre migração, atividades econômicas, redistribuição e reorganização da população no território.

A atividade de produção do bicho-da-seda, introduzido no Brasil em 1848, desenvolveu-se seguindo a dinâmica da cafeicultura, principalmente em São Paulo (PORTO, 2014; VIEIRA, 2014). Essa atividade sericícola chegou ao Paraná na década de 1930, acompanhando os fluxos migratórios que ocuparam e delinearam a porção norte do território paranaense, no contexto de expansão da fronteira agrícola no estado. Inicialmente, atividade de colonos japoneses e descendentes, a sericicultura passou a ser atividade de produtores rurais familiares diversos. A produção da seda constitui-se, atualmente, em uma cadeia produtiva altamente integrada, combinando várias atividades econômicas e diferentes formas de trabalho, desde o cultivo da amoreira, produção do bicho da seda, preparação do fio, até a produção têxtil (SEAB/DERAL, 2015; 2014; 2008).

O Brasil tornou-se um dos principais produtores mundiais de seda no século XX. O estado de São Paulo deixou de ser o principal produtor de casulos durante a década de 1980, quando a produção passa a se concentrar no estado do Paraná e, desde então, o estado tem se mantido como principal exportador brasileiro. Esse processo é marcado por dois momentos: a expansão crescente da produção, entre os anos 1980 e 2010; e o período posterior a 2010, quando começa a se registrar uma redução progressiva da produção, afetada pela variação na demanda mundial da seda.

Consequentemente, ocorreu uma diminuição no número de produtores de casulos, bem como reduz-se o emprego na indústria de fiação da seda. Contudo, há um aumento na produtividade, sobretudo na região Noroeste paranaense, mantendo o volume de exportações. Diante dos efeitos diretos sobre a dinâmica populacional dos municípios produtores, desenvolve-se no estado uma política de apoio ao adensamento da cadeia produtiva da seda, com participação de institutos e universidades estaduais e federais, além da criação, em 2004, da Câmara Técnica do Complexo da Seda, no âmbito do governo estadual. Como efeito, surgiram dessa política, organizações locais e cooperativas, que visam ampliar e articular a rede de produção da seda no estado, integrando a produção local com o mercado mundial (SEAB/DERAL, 2015).

Embora seja uma atividade cujos impactos tenham uma dimensão regional/local, conhecer melhor esses processos fornecerá subsídios para uma maior compreensão da complexidade das transformações ocorridas nos espaços rurais e urbanos de uma determinada região, no contexto paranaense, que tem a maior parte do seu processo histórico de desenvolvimento demográfico, social, econômico, cultural e político vinculada a uma das mais importantes fronteiras agrícolas, em curso no país, ao longo do século XX. 


\section{SEMINÁRIO DE PESQUISA EM CIÊNCIAS HUMANAS - SEPECH \\ Humanidades, Estado e desafios didático-científicos \\ Londrina, 27 a 29 de julho de 2016}

\section{CONTEXTUALIZAÇÃO HISTÓRICA DA SERICICULTURA NO BRASIL}

A atividade sericícola, que compreende a criação do bicho-da-seda voltada para fins têxteis para produção da seda, constitui uma arte milenar originária da China, há mais de três mil anos. A partir do século VI, essa atividade se expande nos países europeus e chega ao Brasil por volta de 1848, quando é criada, no Rio de Janeiro, por Dom Pedro II, a Imperial Companhia Seropédica Fluminense, voltada para a sericicultura. Depois disso, uma segunda iniciativa deu-se, em 1912, com a criação da $1^{\text {a }}$. Estação Experimental de Sericicultura, em Barbacena-MG (PORTO, 2014).

Apesar dessas duas primeiras iniciativas vinculadas à atividade sericícola no Brasil, é somente a partir da década de 1930 que a produção de casulos de bicho-daseda ganha impulso no país, concentrada no estado de São Paulo. Segundo Porto (2014), dois momentos importantes nessa expansão foi a inauguração, em 1923, da S/A Indústria de Seda Nacional, em Campinas, e, em 1940, o estabelecimento da Fiação de Seda Bratac $\mathrm{S} / \mathrm{A}^{3}$, na cidade de Bastos, vinculada à colônia japonesa nesse município.

Posteriormente, um marco importante no avanço da sericicultura no estado do Paraná é a instalação de uma filial da Bratac, na década de 1970, na cidade de Londrina, também financiada e vinculada às comunidades japonesas, existente nas cidades do Norte Paranaense ${ }^{4}$.

Para compreender o sucesso do desenvolvimento da sericicultura, em São Paulo, entre 1940 e 1980, deve-se considerar dois aspectos. De acordo com Porto (2014), por um lado, o contexto da Segunda Guerra Mundial foi um estímulo à produção fabril da seda, devido ao fechamento dos portos asiáticos e europeus e o interesse dos Estados Unidos na aquisição da produção brasileira.

Por outro lado, a sericicultura se desenvolveu, nas diferentes regiões paulistas, de forma complementar à produção cafeeira, e acompanhando a expansão das estradas de ferro, inicialmente no estado de São Paulo, principalmente nas regiões mais a oeste do estado e, posteriormente, no estado do Paraná, concentrando-se na porção norte paranaense.

Reconhecido como o maior polo de sericicultura do Brasil e o maior do Ocidente, o estado do Paraná concentra, atualmente, cerca de $86 \%$ da produção de casulos de bicho-da-seda, especialmente nas regiões situadas na porção norte do território paranaense, onde se destaca o "vale da seda", composto por 29 municípios das regiões Noroeste e Norte do estado e envolvendo famílias vinculadas à pequena propriedade e à agricultura familiar, destacando-se que, de acordo com a Pesquisa da Pecuária Municipal, de 2013, entre os 20 maiores municípios produtores de casulos, dezoito são paranaenses e quatro pertencem ao "vale da seda" (IBGE, 2013).

Como já foi apontado anteriormente, o Brasil tornou-se um dos principais produtores mundiais de seda no século XX, tendo o estado de São Paulo como o principal produtor de casulos até 1980. A partir desse período, o estado do Paraná assume o protagonismo da produção sericícola no contexto nacional, tornando-se o principal produtor e exportador brasileiro.

\footnotetext{
3 O nome Bratac tem origem na Sociedade Colonizadora Brasileira, ou "Brazil Takushoku Kumiai" BRATAC (PORTO, 2014, pg.293).

${ }^{4}$ Informações obtidas no site da empresa: http://www.bratac.com.br/bratac/pt/index.php.
} 


\section{SEMINÁRIO DE PESQUISA EM CIÊNCIAS HUMANAS - SEPECH \\ Humanidades, Estado e desafios didático-científicos \\ Londrina, 27 a 29 de julho de 2016}

Em 2010, há uma redução da produção, afetada pela variação na demanda mundial da seda, com redução no número de produtores de casulos, bem como do emprego na indústria de fiação da seda. Contudo, há um aumento na produtividade, sobretudo na região Noroeste paranaense, mantendo o volume de exportações (SEAB/DERAL, 2015; 2014; 2008).

Com isso, vale ressaltar que a dinâmica da atividade sericícola se encontra, desde a sua fase inicial, influenciada pelo mercado internacional. A figura 1 ilustra a produção mundial no período mais recente.

Destaca-se que, no ano de 2012, os principais produtores de casulos foram a China, Índia, Uzbequistão, Brasil, Tailândia, Irã e Vietnã, sendo que a China e Índia foram responsáveis, respectivamente, por $65 \%$ e $26 \%$ da produção mundial. Nesse ranking, o Brasil ocupou a quarta posição, constituindo-se no único país ocidental entre os principais produtores sericícola (SEAB/DERAL, 2015).

Por sua vez, de acordo com os dados referentes ao ano de 2010, os principais destinos da produção de "fios de seda brasileiros" compreendem o Japão (principal importador), Vietnã e Itália; em menor proporção, destacam-se França, Coréia do Sul, China e Turquia.

Considerando, em segundo lugar, a exportação de "tecidos e outros produtos têxteis de seda", a diversidade de destinos é maior, envolvendo 55 países, com destaque para os Estados Unidos e Angola (SEAB/DERAL, 2010).

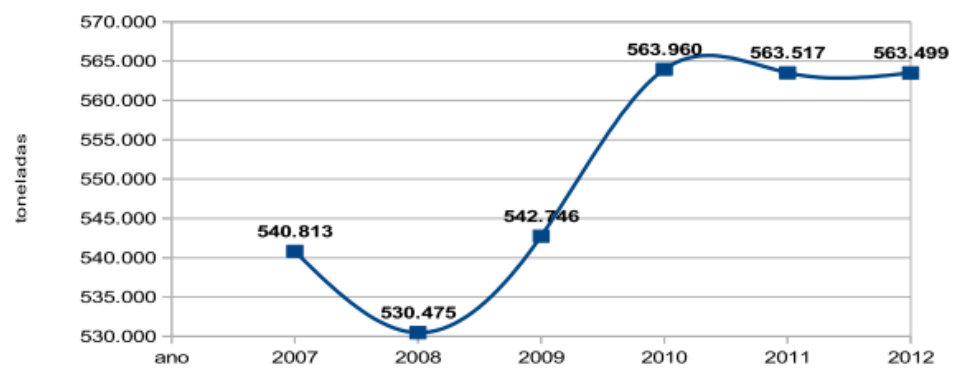

Fonte: FAOSTAT, 2014

Figura 1: Produção mundial de casulos de bicho-da-seda (em toneladas), $2007-2012^{5}$

Considerando a produção nacional dos casulos, no período mais recente, observa-se que, apesar da contínua diminuição da produção, entre 2007 e 2015, o estado do Paraná mantém a posição de principal estado produtor, nos últimos 15 anos.

\footnotetext{
${ }^{5}$ SEAB/DERAL, 2015, pg.2.
} 


\section{SEMINÁRIO DE PESQUISA EM CIÊNCIAS HUMANAS - SEPECH \\ Humanidades, Estado e desafios didático-científicos \\ Londrina, 27 a 29 de julho de 2016}

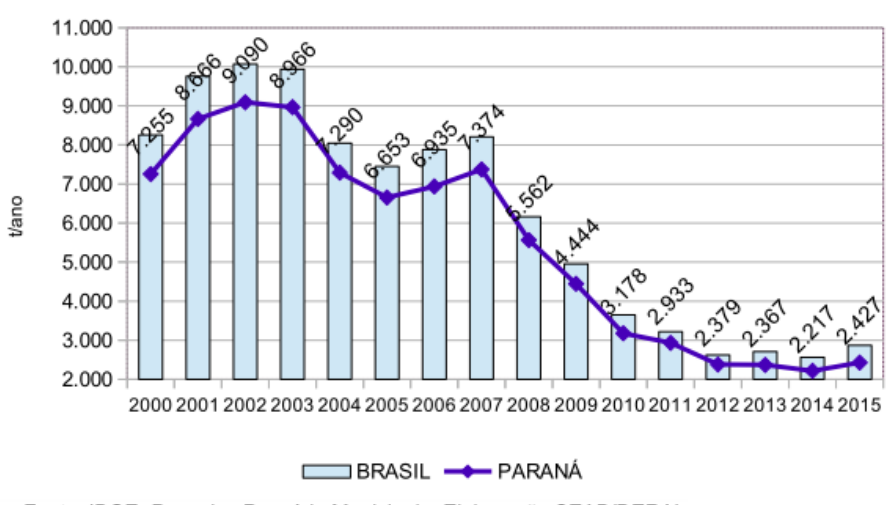

Fonte: IBGE- Pesquisa Pecuária Municipal - Elaboração SEAB/DERAL

Figura 2: Participação do Paraná na produção nacional de casulos de bicho-da-seda verdes (em toneladas), 2000-2015

Apresentado esse quadro geral sobre a inserção da produção nacional no contexto mundial, no período recente, no período recente, na subseção seguinte, será abordada o perfil da atividade sericícola, a partir de 1970, em dois conjuntos de municípios paranaenses: o primeiro grupo refere-se aos municípios que compõem o Vale da Seda e o segundo grupo é composto por aqueles que, em 2014, foram os maiores produtores de casulos do bicho-da-seda, no estado.

\section{POPULAÇÃO E MUNICÍPIOS NA EXPANSÃO DA SERICICULTURA PARANAENSE}

Antes de falarmos da sericicultura paranaense, vale apresentar algumas considerações sobre a fonte de dados sobre a produção de casulos de bicho-da-seda e, a partir disso, ilustrar o crescimento dessa atividade nas duas principais Unidades da Federação. Nesse sentido, destaca-se que as fontes de dados exploradas foram os Censos Agrícolas dos anos de 1940 a 2006 e as Pesquisas da Pecuária Municipal de 2010, 2013 e 2014.

Com relação aos censos agrícolas, observa-se, ainda, que, a sua primeira realização ocorre conjuntamente com o censo demográfico de 1920. Porém, esse ano não é contemplado neste trabalho porque é somente a partir do censo agrícola de 1940 que se passa a inquerir sobre a produção de casulos de bicho-da-seda, quando a informação é apresentada para Grandes Regiões e Unidades da Federação. A partir do censo de 1950, por sua vez, é possível levantar essa informação em nível municipal.

\footnotetext{
${ }^{6}$ SEAB/DERAL, 2015, pg.9.
} 


\section{SEMINÁRIO DE PESQUISA EM CIÊNCIAS HUMANAS - SEPECH \\ Humanidades, Estado e desafios didático-científicos \\ Londrina, 27 a 29 de julho de 2016}

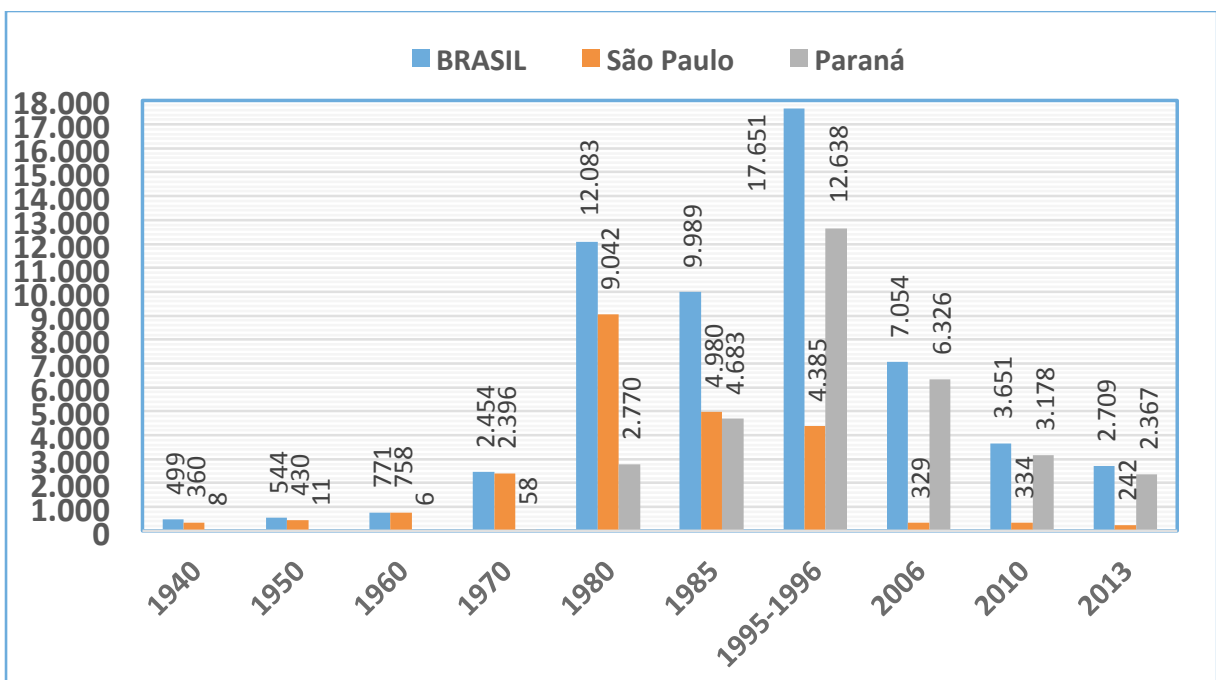

Gráfico 1: Produção de casulos de bicho-da-seda (ton.)

Brasil, São Paulo e Paraná - 1940-2014

Fonte de dados: IBGE. Censos agrícolas de 1940 a 2006; Pesquisa da Pecuária Municipal de 2010 e 2014.

[Elaboração própria]

De acordo com os dados da Gráfico 1, observa-se que a produção nacional de casulos de bicho-da-seda, ao longo dos quatro primeiros censos agropecuários, apresentou um crescimento tímido, mas contínuo, saindo de 499 toneladas, em 1940, e alcançando o patamar de 2.400 toneladas, em 1970, sendo São Paulo o estado no qual se concentrou essa produção sericícola. Neste mesmo período, a produção paranaense apresentou uma dinâmica irregular e um peso quantitativo pouco significativo.

Por sua vez, a partir de 1980, a sericicultura brasileira assistiu a importantes mudanças, tanto em termos de volume da produção nacional, quanto em relação à participação dos dois principais estados envolvido nessa atividade.

Assim, no período de 1980 a 1995-96, o país registrou um grande salto na produção de casulos de bicho-da-seda: em 1980, a produção chegou a $12 \mathrm{ml}$ toneladas; em 1985, aproximadamente a 10 mil toneladas; e, no censo de 1995-1996, a atividade sericícola ultrapassou o patamar de 17 mil toneladas.

Paralelamente, observa-se o crescimento da participação do Paraná nesta produção: enquanto, em 1980, o estado concentrou cerca de $23 \%$ da atividade sericícola, em 1985, Paraná e São Paulo dividem, de forma quase equitativa, mais de 95\% da produção nacional e, por fim, em 1995-96, o Paraná inverte a posição com São Paulo, passando a concentrar aproximadamente $72 \%$ de toda a produção de casulos de bicho-da-seda.

Dois fatores podem ter influenciado essa mudança: um de cunho econômica e outro, demográfica-migratória. Quanto ao fator econômico, se podemos destacar a criação das unidades fabris em Campinas (em 1923) e em Bastos (1940) como um momento importante para a expansão da sericultura no estado de São Paulo, podemos destacar a criação de uma unidade da Bratac, no município de Londrina (PR), na década de 1970, conforme citado na seção anterior.

Quanto à dimensão demográfica-migratória, considerando alguns estudos sobre crescimento, redistribuição e reorganização espacial da população no país e no Paraná 


\section{SEMINÁRIO DE PESQUISA EM CIÊNCIAS HUMANAS - SEPECH \\ Humanidades, Estado e desafios didático-científicos \\ Londrina, 27 a 29 de julho de 2016}

(BALTAR e BALTAR, 2014; IPARDES, 2006; MAGALHÃES, 2003; CUNHA e BAENINGER, 2006; FARIA, 1991; MARTINE e CAMARGO, 1984), destaca-se que a população paranaense assistiu a um intenso crescimento ao longo do século XX, principalmente entre 1940 e 1970, em grande parte, em função da expansão da fronteira agrícola na porção norte do estado.

Ao longo da década de 1970, o estado vivenciou importantes mudanças econômicas: por um lado, ocorreu a crise e esgotamento da fronteira agrícola e, por outro, uma mudança no eixo econômico a partir da qual o estado passa a concentrar seus investimentos em atividades industriais e urbanas, principalmente, na área compreendida pela região metropolitana de Curitiba (BALTAR e BALTAR, 2014; IPARDES, 2006; 2004).

Com isso, pretende-se destacar que o elevado crescimento da produção sericícola no estado do Paraná, entre 1980 e 1995, pode ter se beneficiado do crescimento populacional que acompanhou a fronteira agrícola paranaense, uma vez que se tratou de uma expansão demográfica baseada, principalmente, na pequena propriedade rural. Complementarmente, diferentes estudos específicos sobre a sericicultura (PORTO, 2014; VIEIRA, 2014; SEAB/DERAL, 2015; 2014; 2010; 2008) apontam a importância da atividade sericícola se expandir de forma articulada às atividades cafeeiras, desde a década de 1930, como uma alternativa de assegurar o sustento e a permanência dos pequenos produtores rurais e familiares, nos períodos de entressafra do café.

Já o período mais recente, compreendido pelos anos de 2006-2013, é marcado por uma queda contínua na produção nacional de casulos e, ao mesmo tempo, uma concentração cada vez maior no estado do Paraná ${ }^{7}$. Os estudos especializados supracitados deixam clara a influência do mercado internacional na dinâmica da produção nacional, destacando a produção chinesa como uma das principais concorrentes do Brasil nesse nicho. Porém apontam também diversos fatores internos que contribuíram, e ainda contribuem, para essa redução na atividade.

Dentre esses fatores, o de maior interesse para os propósitos desse trabalho refere-se à dinâmica demográfica das principais regiões sericicultoras, situadas na porção norte do território paranaense. Nesse sentido, relatórios oficiais de acompanhamento do governo estadual apontam o êxodo rural, especialmente de jovens, em curso nessas regiões, como um dos entraves para uma maior expansão da atividade no estado (SEAB/DERAL, 2015; 2014; 2010; 2008).

Apesar desse quadro de redução da produção sericícola no país e no estado do Paraná, o Brasil mantém a posição de maior produtor ocidental de casulos de bicho-daseda e, no contexto nacional, o Paraná concentra mais de $80 \%$ da produção, a qual é totalmente exportada no comércio internacional.

\footnotetext{
${ }^{7}$ De acordo com SEAB/DERAL (2015), no período entre 2012 e 2015, o Paraná concentrou, em média, $86,5 \%$ da produção sericícola do país, seguido por São Paulo (9,0\%), Mato Grosso do Sul (4,0\%) e Santa Catarina $(0,02 \%)$.
} 


\section{SEMINÁRIO DE PESQUISA EM CIÊNCIAS HUMANAS - SEPECH \\ Humanidades, Estado e desafios didático-científicos \\ Londrina, 27 a 29 de julho de 2016}

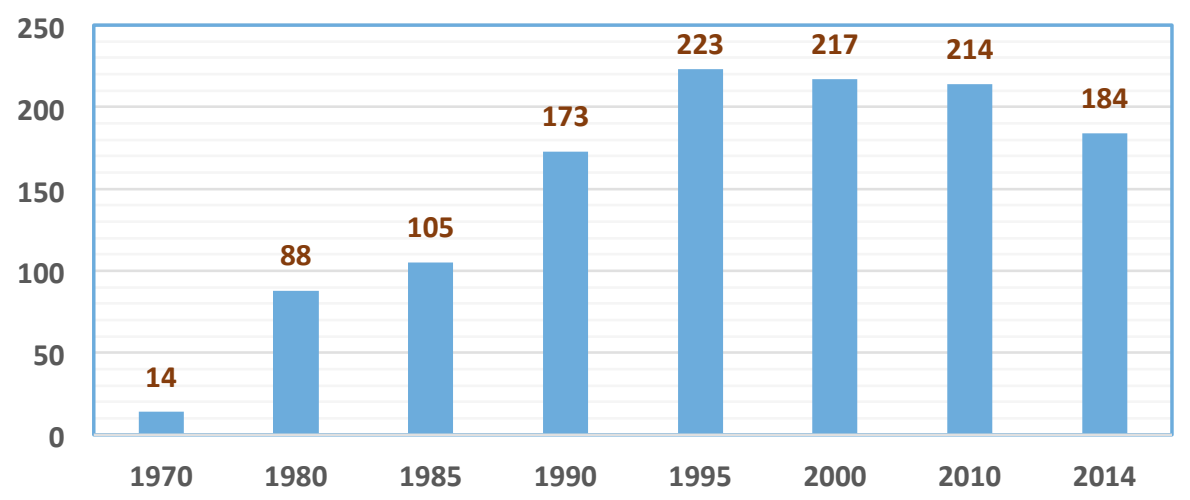

Gráfico 2: Quantidade de municípios paranaenses envolvidos na sericicultura Paraná, 1970-2014

Fonte de dados: IBGE. Censos agrícolas de 1970 a 2000; Pesquisa da Pecuária Municipal de 2010 e 2014.

[Elaboração própria]

Para finalizar, destaca-se que, entre 1970 e 2014, houve um rápido crescimento na quantidade de municípios paranaenses envolvidos na sericicultura. Assim, de acordo com o gráfico 2, observa-se que, enquanto em 1970, eram apenas 14 municípios que produziam casulos de bicho-da-seda, em 1995, esse número alcançou seu ápice, com 223 municípios sericícolas, correspondendo a 56\% dos municípios paranaenses. A partir de 1995, o número de municípios com produção de casulos diminuiu, chegando, em 2014, a envolver 184 municípios.

Em termos de produtores sericicultores, no período mais recente, assiste-se a um decréscimo significativo, conforme ilustrado pelo gráfico 3. Nos últimos doze anos, a sericicultura paranaense vem passando por um decréscimo paulatino na quantidade de produtores rurais envolvidos com a atividade.

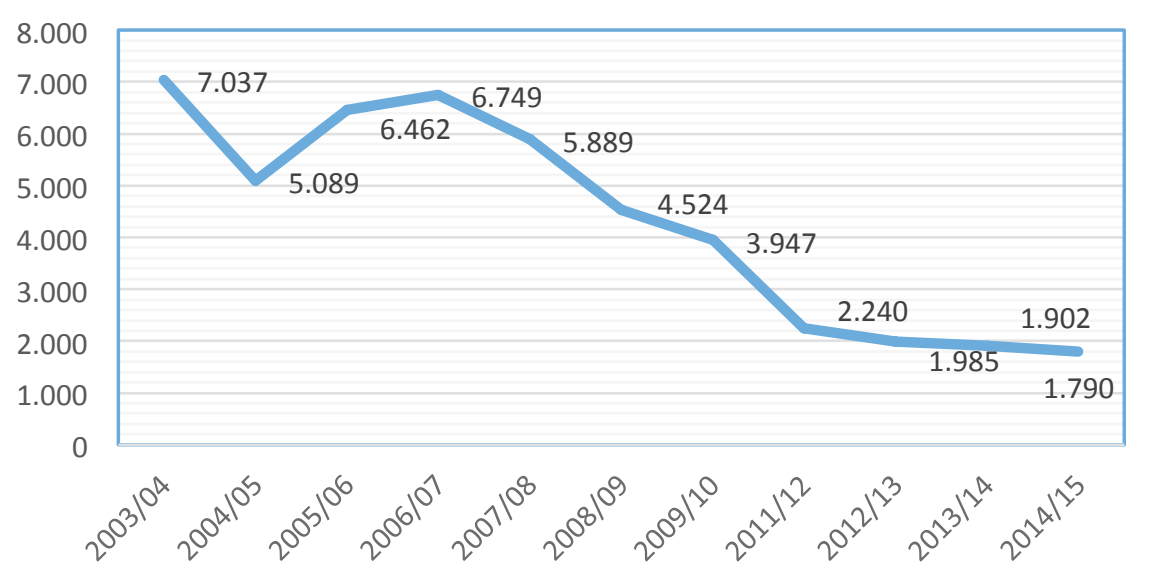

Gráfico 3: Número de sericicultores no Paraná. Safras de 2003 a 2015 Fonte de dados: SEAB/DERAL, 2015; 2010; 2008. [Elaboração própria]

. Tal movimento, por sua vez, estaria diretamente relacionado com a dinâmica demográfica dos municípios envolvidos na produção, caracterizados por um êxodo rural 


\section{SEMINÁRIO DE PESQUISA EM CIÊNCIAS HUMANAS - SEPECH \\ Humanidades, Estado e desafios didático-científicos \\ Londrina, 27 a 29 de julho de 2016}

ainda em curso, dentro do qual a saída dos jovens é o que mais impacta a atividade sericícola no período recente (SEAB/DERAL, 2015; 2010; 2008).

\section{O "VALE DA SEDA" E OS MAIORES PRODUTORES SERICÍCOLAS PARANAENSES}

Para os propósitos deste estudo, optou-se por analisar as dinâmicas demográficas e da sericicultura no estado a partir da consideração de dois grupos de municípios: o primeiro compreendendo os municípios que compõem o chamado "vale da seda" e o segundo, composto pelos maiores produtores de casulo, em 2014, de acordo com o censo agropecuário.

\begin{tabular}{|l|l|}
\hline MUNICÍPIOS - VALE DA SEDA & $\begin{array}{l}\text { MUNICÍPIOS MAIORES PRODUTORES } \\
\mathbf{( 2 0 1 4 )}\end{array}$ \\
\hline - 29 Municípios & -20 Municípios \\
- Norte Central e Noroeste & $\begin{array}{l}\text { Norte Central, Noroeste, Norte Pioneiro, } \\
\text { Oeste e Centro-Sul }\end{array}$ \\
- menor pop $(2010)=1.409$ habitantes & - menor pop $(2010)=1.862$ habitantes \\
- maior pop $(2010)=357.077$ habitantes & - maior pop $(2010)=26.615$ habitantes \\
- \% municípios até 20 mil habitantes: & \\
$65 \%$ & - \% municípios até 20 mil habitantes: $85 \%$ \\
\hline
\end{tabular}

Quadro 1: Caracterização dos grupos de municípios

Fonte de dados brutos: Censo demográfico de 2010; Pesquisa da Pecuária Municipal, 2014. [Elaboração própria].

O "vale da seda" é uma entidade civil privada criada, em 2009, com a função de promover o desenvolvimento da cadeia produtiva da sericicultura, envolvendo pequenos produtores familiares de 29 municípios localizados na Bacia Hidrográfica do Rio Pirapó ${ }^{8}$, além de constituir uma marca comercial de produtos à base da seda.

Por sua vez, decidiu-se, contrastar esses municípios com o grupo formado pelos maiores produtores sericícolas, em 2014. O propósito deste exercício é buscar elementos que indiquem a vinculação entre a sericicultura e a dinâmica demográficamigratória dos municípios envolvidos nessa atividade.

Assim, com relação ao quadro 1, o que se destaca, inicialmente, é a abrangência regional dos dois grupos de municípios. Enquanto o "vale da seda", por compreender a área de uma bacia hidrográfica específicas, seus municípios situam-se no Norte Central e Noroeste, duas mesorregiões limítrofes, o grupo formado pelos maiores produtores sericícolas compreende municípios situados em mais mesorregiões: Norte Central, Noroeste, Norte Pioneiro, Oeste e Centro-Sul.

Quanto ao porte populacional, enquanto, no "vale da seda", o menor município possui menos de 2.000 habitantes, em 2010, o maior possuía mais de 300 mil habitantes; além disso, $65 \%$ dos municípios desse grupo possuía população inferior a 20 mil habitantes. Por sua vez, o grupo dos maiores produtores compreende somente

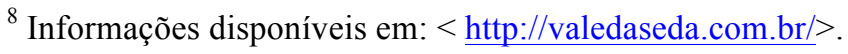




\section{SEMINÁRIO DE PESQUISA EM CIÊNCIAS HUMANAS - SEPECH \\ Humanidades, Estado e desafios didático-científicos \\ Londrina, 27 a 29 de julho de 2016}

municípios com população inferior a 30 mil habitantes, sendo que $85 \%$ desses municípios possuía menos de 20 mil habitantes.

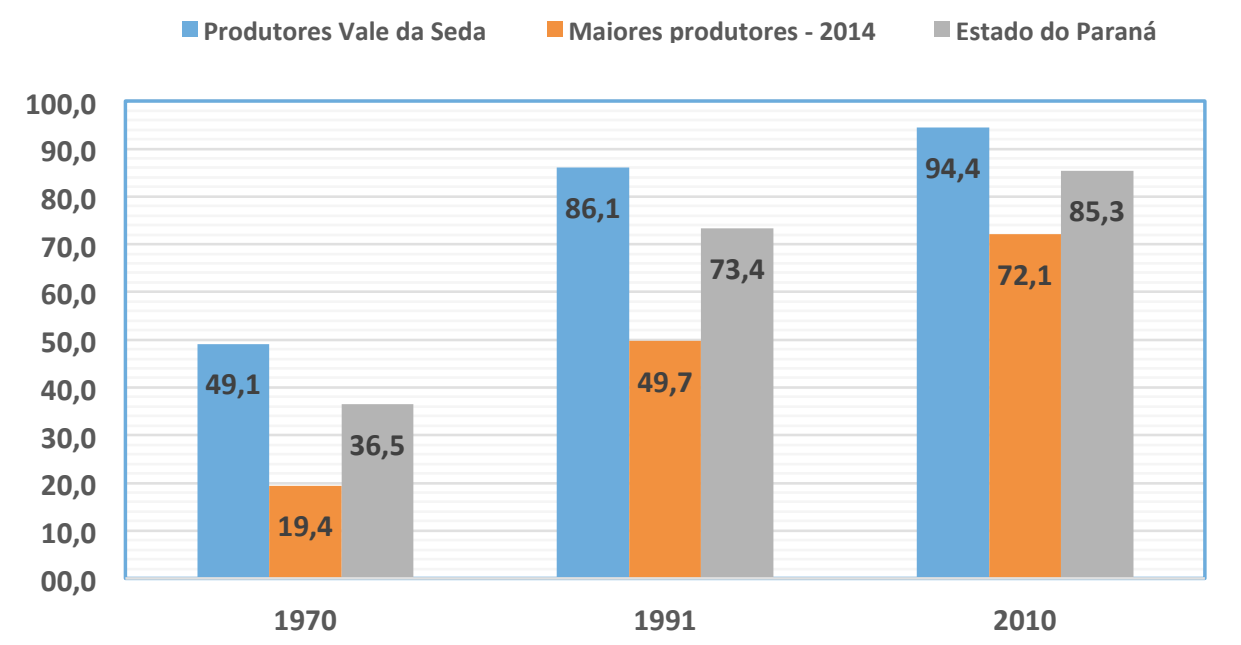

Gráfico 4: Taxa de urbanização - Paraná, por grupos de municípios 1970-2010

Fonte de dados: IBGE. Censos demográficos, 1970-2010. [Elaboração própria]

Considerando o processo de urbanização, entre 1970 e 2010, observamos diferentes dinâmicas. Nesse sentido, a primeira observação a ser feira refere a intensidade com que esse fenômeno se processa no estado: em 1970, o estado do Paraná quase dois terços da sua população vivendo em áreas rurais ${ }^{9}$. Em 1991, a urbanização do estado alcança o patamar de $73 \%$ e, em 2010 , a concentração populacional em áreas urbanas chega a $85 \%$.

Tomando os dois grupos de municípios selecionados tem-se dinâmicas distintas quanto ao processo de urbanização. Assim, por um lado, o grupo de municípios do "vale da seda", nos três momentos censitários, possuía uma taxa de urbanização superior ao nível de urbanização do estado. Por outro, o grupo dos maiores produtores, contrariamente, nos três períodos, apresentou grau de urbanização inferior ao nível estadual.

\footnotetext{
${ }^{9}$ A transição urbana do estado do Paraná ocorrerá somente em 1980, quando, aproximadamente, 59\% da população passa a se concentrar em áreas urbanas. (BALTAR e BALTAR, 2014).
} 


\section{SEMINÁRIO DE PESQUISA EM CIÊNCIAS HUMANAS - SEPECH \\ Humanidades, Estado e desafios didático-científicos \\ Londrina, 27 a 29 de julho de 2016}

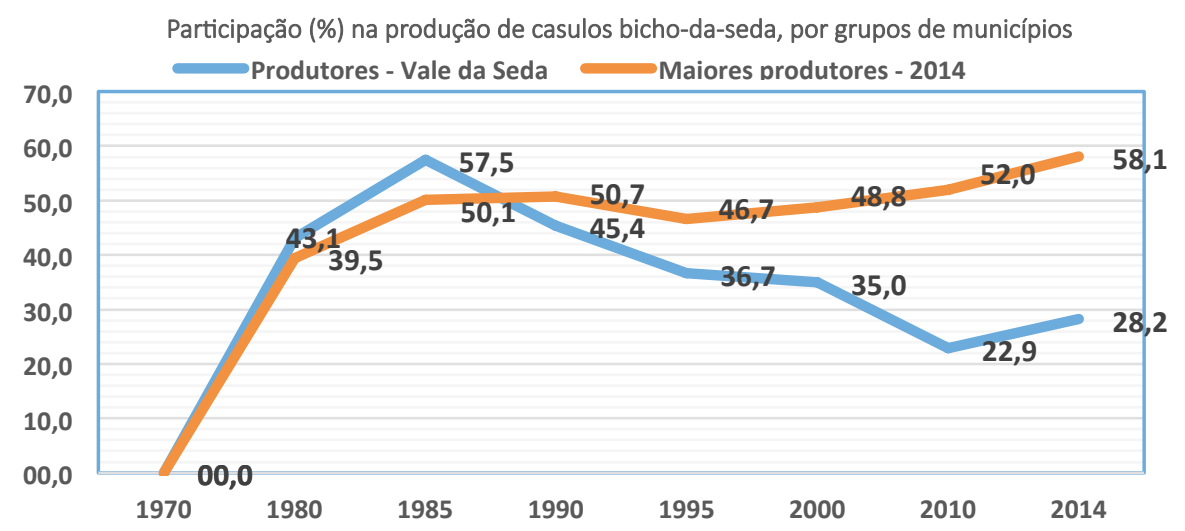

Gráfico 5: Participação (\%) na produção de casulos bicho-da-seda, por grupos de municípios

Fonte de dados: IBGE. Censos agrícolas de 1970 a 2000; Pesquisa da Pecuária Municipal de 2010 e 2014. [Elaboração própria]

Contrastando a informação sobre o grau de urbanização com a participação dos dois grupos de municípios, na produção estadual de casulos de bicho-da-seda, conforme o gráfico5, observam-se diferentes situações: em primeiro lugar, quando consideramos os municípios do "vale da seda", que apresentaram uma dinâmica de urbanização com índices superiores à média estadual, registraram uma participação decrescente, principalmente a partir de 1985, na produção sericícola.

Em segundo lugar, quando analisamos o grupo dos maiores produtores de casulos, que vivenciaram um processo de urbanização menos intenso em termos relativos, observamos que a sua participação aumenta, com algumas oscilações, a partir de 1985.

Duas observações podem ser feitas: o grupo dos municípios do "vale da seda", tomados numa perspectiva histórica, tiveram um protagonismo na produção sericicultora durante a década de 1980, porém a importância desse grupo diminuiu progressivamente, a partir de 1990. Destaca-se, ainda, que a criação da entidade "vale da seda", foi criada em 2009 - momento em que produção em conjunto do grupo encontrava-se bem em baixa, o que pode ter contribuído para o pequeno aumento na fase mais recente.

Por fim, o grupo dos maiores produtores, quando tomados em conjunto, passou a ganhar importância no contexto da sericicultura, a partir da segunda metade da década de 1980, chegando a concentrar, em 2014, quase $60 \%$ da produção paranaense de casulos de bicho-da-seda. Argumenta-se, neste trabalho, que essa maior concentração dessa atividade neste grupo estaria relacionada com a maior presença relativa da população rural nestes municípios, o que só pode ser verificado com um aprofundamento da pesquisa. 


\section{SEMINÁRIO DE PESQUISA EM CIÊNCIAS HUMANAS - SEPECH \\ Humanidades, Estado e desafios didático-científicos \\ Londrina, 27 a 29 de julho de 2016}

\section{CONSIDERAÇÕES FINAIS}

A realização deste trabalho correspondeu aos primeiros esforços no sentido de se conhecer as dinâmicas demográficas-migratórias vinculadas à expansão da atividade sericicultora no estado do Paraná.

Através do quadro da produção sericícola nacional, buscou-se identificar as principais áreas de expansão dessa atividade e, no estado do Paraná, no contraste entre dois diferentes grupos de municípios - "vale da seda" e os maiores produtores no período recente - buscou-se identificar as suas vinculações com a dinâmica demográfica dos municípios envolvidos.

Argumenta-se que há uma relação entre essas duas dinâmicas de forma que a dinâmica demográfica-migratória ora favoreceu a expansão das atividades sericícolas, ora constituiu-se num dos fatores do seu decréscimo no período mais recente.

Por fim, busca-se, com o aprofundamento deste estudo, o acúmulo de subsídios para a compreensão da complexidade e da diversidade presentes no processo de mudança do campo e da ruralidade no estado do Paraná.

\section{REFERÊNCIAS BIBLIOGRÁFICAS}

BALHANA, A.; MACHADO, B.P.; WESTPHALEN, C. História do Paraná. Curitiba: Grafipar, 1969.

BALTAR, C.S.; BALTAR, R. O processo de criação de municípios como parâmetro para a análise da dinâmica demográfica e econômica das regiões do estado do Paraná. XIX Encontro Nacional de Estudos de População. Anais... São Pedro, ABEP, 2014. Disponível em: <http://abep.info/files/trabalhos/trabalho completo/TC-6-11-365180.pdf>.

CUNHA, J.M.P.; BAENINGER, R. Cenários da migração no Brasil nos anos 90. Cadernos CRH, Salvador, vol.18, n.43, p.87-101, Jan/Abril 2005.

FARIA, V.E. Cinquenta anos de urbanização no Brasil: Tendências e perspectivas. Novos Estudos, no.29, março de 1991. Disponível em: < http://novosestudos.uol.com.br/v1/files/uploads/contents/63/20080624_cinquenta_anos_ de_urbanizacao.pdf $>$.

INSTITUTO BRASILEIRO DE GEOGRAFIA E ESTATÍSTICA (IBGE). Pesquisa da pecuária municipal. Rio de Janeiro: IBGE, vol.41, 2013.

INSTITUTO PARANAENSE DE DESENVOLVIMENTO ECONÔMICO E SOCIAL (IPARDES). Os vários Paranás: identificação de espacialidades socioeconômicoinstitucionais como subsídios a políticas de desenvolvimento regional. Curitiba : IPARDES, 2006. 


\section{SEMINÁRIO DE PESQUISA EM CIÊNCIAS HUMANAS - SEPECH \\ Humanidades, Estado e desafios didático-científicos \\ Londrina, 27 a 29 de julho de 2016}

Leituras regionais. Mesorregiões geográficas paranaenses: Sumário executivo. Curitiba : IPARDES, 2004

MARTINE, G.; CAMARGO, L. Crescimento e distribuição da população brasileira: tendências recentes. Revista Brasileira de Estudos de População. Vol.1, n.1/2, p.99143, 1984.

NADALIN, S.O. Paraná: ocupação do território, população e migrações. Curitiba: Secretaria de Estado da Educação, 2002.

PORTO, A.J. Sericicultura no estado de São Paulo. Boletim Indústr. Anim., Nova Odessa, volume 71, no.3, p.291-302, 2014. (Revisão bibliográfica).

SEAB/DERAL. Sericicultura no Estado do Paraná. Safra 2014/2015. Curitiba: Secretaria de Estado da Agricultura e do Abastecimento/Departamento de Economia Rural, 2015.

- Sericicultura. Curitiba: Secretaria de Estado da Agricultura e do Abastecimento/Departamento de Economia Rural, 2014.

- Sericicultura. Curitiba: Secretaria de Estado da Agricultura e do Abastecimento/Departamento de Economia Rural, 2010.

. Sericicultura. Safra 2008/2009. Curitiba: Secretaria de Estado da Agricultura e do Abastecimento/Departamento de Economia Rural, 2008.

VIEIRA, A.K. Arranjos produtivos na sericicultura brasileira. Curitiba, 2014. 58f. Monografia - Ciências Sociais Aplicadas, Faculdade de Ciências Econômicas, Universidade Federal do Paraná, 2014.

WACHOWICZ, R. História do Paraná. Curitiba : Imprensa Oficial do Paraná, 2002. 